American Journal of Biochemistry and Biotechnology 4 (3):250-254, 2008

ISSN 1553-3468

(C) 2008 Science Publications

\title{
Biodiesel Fuel Production from Algae as Renewable Energy
}

\author{
A.B.M. Sharif Hossain, Aishah Salleh, \\ Amru Nasrulhaq Boyce, Partha chowdhury and Mohd Naqiuddin \\ Biotecnology Laboratory, Institute of Biological Sciences, \\ Faculty of Science, University of Malaya, Kuala Lumpur 50603, Malaysia
}

\begin{abstract}
Biodiesel is biodegradable, less $\mathrm{CO}_{2}$ and $\mathrm{NO}_{\mathrm{x}}$ emissions. Continuous use of petroleum sourced fuels is now widely recognized as unsustainable because of depleting supplies and the contribution of these fuels to the accumulation of carbon dioxide in the environment. Renewable, carbon neutral, transport fuels are necessary for environmental and economic sustainability. Algae have emerged as one of the most promising sources for biodiesel production. It can be inferred that algae grown in $\mathrm{CO}_{2}$-enriched air can be converted to oily substances. Such an approach can contribute to solve major problems of air pollution resulting from $\mathrm{CO}_{2}$ evolution and future crisis due to a shortage of energy sources. This study was undertaken to know the proper transesterification, amount of biodiesel production (ester) and physical properties of biodiesel. In this study we used common species Oedogonium and Spirogyra to compare the amount of biodiesel production. Algal oil and biodiesel (ester) production was higher in Oedogonium than Spirogyra sp. However, biomass (after oil extraction) was higher in Spirogyra than Oedogonium sp. Sediments (glycerine, water and pigments) was higher in Spirogyra than Oedogonium sp. There was no difference of pH between Spirogyra and Oedogonium sp. These results indicate that biodiesel can be produced from both species and Oedogonium is better source than Spirogyra sp.
\end{abstract}

Key words: Algal oil, biodiesel, transesterification, glycerine

\section{INTRODUCTION}

Bioenergy is one of the most important components to mitigate greenhouse gas emissions and substitute of fossil fuels ${ }^{[1]}$. The need of energy is increasing continuously, because of increases in industrialization and population. The basic sources of this energy are petroleum, natural gas, coal, hydro and nuclear $^{[2]}$. The major disadvantage of using petroleumbased fuels is atmospheric pollution created by the use of petroleum diesel. Petroleum diesel combustion is a major source of greenhouse gas (GHG). Apart from these emissions, petroleum diesel is also major source of other air contaminants including $\mathrm{NO}_{\mathrm{x}}, \mathrm{SO}_{\mathrm{x}}, \mathrm{CO}$, particulate matter and volatile organic compounds ${ }^{[3]}$.

Biomass is one of the better sources of energy ${ }^{[2]}$. Large-scale introduction of biomass energy could contribute to sustainable development on several fronts, environmentally, socially and economic ${ }^{[4]}$. Biodiesel (monoalkyl esters) is one of such alternative fuel, which is obtained by the transesterification of triglyceride oil with monohydric alcohols. It has been well-reported that biodiesel obtained from canola and soybean, palm, sunflower oil, algal oil as a diesel fuel substitute ${ }^{[5,6]}$. Biodiesel is a nontoxic and biodegradable alternative fuel that is obtained from renewable sources. Biodiesel fuel can be prepared from waste cooking oil, such as palm, soybean, canola, rice bran, sunflower, coconut, corn oil, fish oil, chicken fat and algae ${ }^{[7]}$ which would partly decrease the dependency on petroleum-based fuel.

The burning of an enormous amount of fossil fuel has increased the $\mathrm{CO}_{2}$ level in the atmosphere, causing global warming. Biomass has been focused on as an alternative energy source, since it is a renewable resource and it fixes $\mathrm{COz}$ in the atmosphere through photosynthesis. If biomass is grown in a sustained way, its combustion has no impact on the $\mathrm{CO}_{2}$ balance in the atmosphere, because the $\mathrm{CO}_{2}$ emitted by the burning of biomass is offset by the $\mathrm{CO}_{2}$ fixed by photosynthesis ${ }^{[8,9]}$. Among biomass, algae (macro and microalgae) usually have a higher photosynthetic efficiency than other biomass ${ }^{[10]}$.

Shay ${ }^{[10]}$ reported that algae were one of the best sources of biodiesel. In fact algae are the highest yielding feedstock for biodiesel. It can produce up to

Corresponding Author: A.B.M. Sharif Hossain, Biotecnology Laboratory, Institute of Biological Science, Faculty of Science, University of Malaya, Kuala Lumpur 50603, Malaysia Tel: +603-7967-4356 Fax: +603-7967-4178 
250 times the amount of oil per acre as soybeans. In fact, producing biodiesel from algae may be only the way to produce enough automotive fuel to replace current gasoline usage. Algae produce 7 to 31 time greater oil than palm oil. It is very simple to extract oil from algae. The best algae for biodiesel would be microalgae. Microalgae are an organism capable of photosynthesis that is less than $2 \mathrm{~mm}$ in diameter. Macroalgae, like seaweed, is not as widely used in the production of biodiesel. Microalgae has much more oil than macroalgae and it is much faster and easier to grow $^{[10]}$.

Microalgae can provide several different types of renewable biofuels. These include methane produced by anaerobic digestion of the algal biomass ${ }^{[6]}$ biodiesel derived from microalgal oil ${ }^{[1,12,13]}$ and photobiologically produced biohydrogen ${ }^{[14,15]}$. The idea of using microalgae as a source of fuel is not new ${ }^{[16,17]}$ but it is now being taken seriously because of the escalating price of petroleum and, more significantly, the emerging concern about global warming that is associated with burning fossil fuels ${ }^{[18]}$. No literatures are found regarding present research such as biodiesel from macroalgae having species Oedigonium and Spirogyra. That is why we have done the research to know the proper transesterification, amount of biodiesel production (ester) and physical properties (yield of biodiesel, glycerine and sediments) of biodiesel from algae.

\section{MATERIALS AND METHODS}

Site: The experiment was carried out in the laboratory of Bioresource Science, Department of Biotechnology, Institute of Biological Science, Faculty of Science, University of Malaya, Kuala Lumpur, Malaysia.

Sample collection: Two Petri dishes Algae (Oedogonium and Spirogyra sp., 26.5 and $20.0 \mathrm{~g}$ ) were collected from the Phycology laboratory, Institute of Biological Science, Faculty of Science, University of Malaya, Kuala Lumpur, Malaysia.

Oil extraction: Algae were ground with motor and pestle as much as possible. The ground algae were dried for $20 \mathrm{~min}$ at $80^{\circ} \mathrm{C}$ in a incubator for releasing water. Hexane and ether solution (20 and $20 \mathrm{~mL}$ ) were mixed with the dried ground algae to extract oil. Then the mixture was kept for $24 \mathrm{~h}$ for settling.

Biomass collection: The biomass was collected after filtration and weighted.
Evaporation: The extracted oil was evaporated in vaccu to release hexane and ether solutions using rotary evaporator.

Mixing of catalyst and methanol: $0.25 \mathrm{~g} \mathrm{NaOH}$ was mixed with $24 \mathrm{~mL}$ methanol and stirred properly for $20 \mathrm{~min}$.

Biodiesel production: The mixture of catalyst and methanol was poured into the algal oil in a conical flask. The following reaction and steps were followed: ${ }^{[19]}$

Transesterification: The reaction process is called transesterification. The conical flask containing solution was shaken for $3 \mathrm{~h}$ by electric shaker at 300rpm.

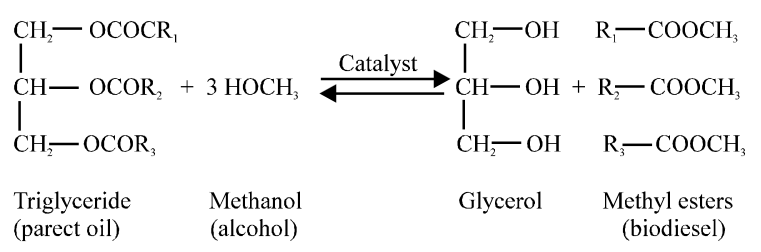

Shetteling: After shaking the solution was kept for $16 \mathrm{~h}$ to settle the biodiesel and sediment layers clearly.

Seperation of biodiesel: The biodiesel was separated from sedimentation by flask separator carefully. Quantity sedimeant (glycerine, pigments, etc.) was measured.

Washing: Biodiesel was washed by $5 \%$ water until it was become clean.

Drying: Biodiesel was dried by using dryer and finally kept under the running fan for $12 \mathrm{~h}$.

Storage: Biodiesel production was measured by using measuring cylinder, $\mathrm{pH}$ was measured and stored for analysis.

\section{RESULTS AND DISCUSSION}

Percent Dry weight of algae (before oil extraction) was higher in Oedogonium than in Spirogyra sp. (Table 1). Extracted oil was higher in Oedogonium than in Spirogyra sp. However, biomass (after oil extraction) was lower in Oedogonium than in Spirogyra sp. (Table 1).

Biodiesel production (methyl ester) was found maximum in Oedogonium sp. and minimum in Spirogyra sp. (Fig. 1). 
Table 1: Measurement of fresh and dry weight, extracted oil and biomass of algae [Petri dish size was same. Diameter was 7.5 and height $1 \mathrm{~cm}]$

\begin{tabular}{lllll}
\hline & $\begin{array}{l}\text { Fresh wt/ } \\
\text { petridish }(\mathrm{g})\end{array}$ & $\begin{array}{l}\text { Dry } \\
\text { weight }\end{array}$ & $\begin{array}{l}\text { Extracted } \\
\text { oil }\end{array}$ & Biomass \\
Treatments & 24.5 & $8.09(\mathrm{~g})$ & $1.8(\mathrm{~g})$ & $3.5(\mathrm{~g})$ \\
Spirogyra sp. & & $33.0(\%)$ & $7.3(\%)$ & $43.3(\%)$ \\
& & $11.3(\mathrm{~g})$ & $3.0(\mathrm{~g})$ & $3.8(\mathrm{~g})$ \\
Oedogonium sp. & 32.4 & $34.8(\%)$ & $9.2(\%)$ & $33.6(\%)$ \\
& & & &
\end{tabular}

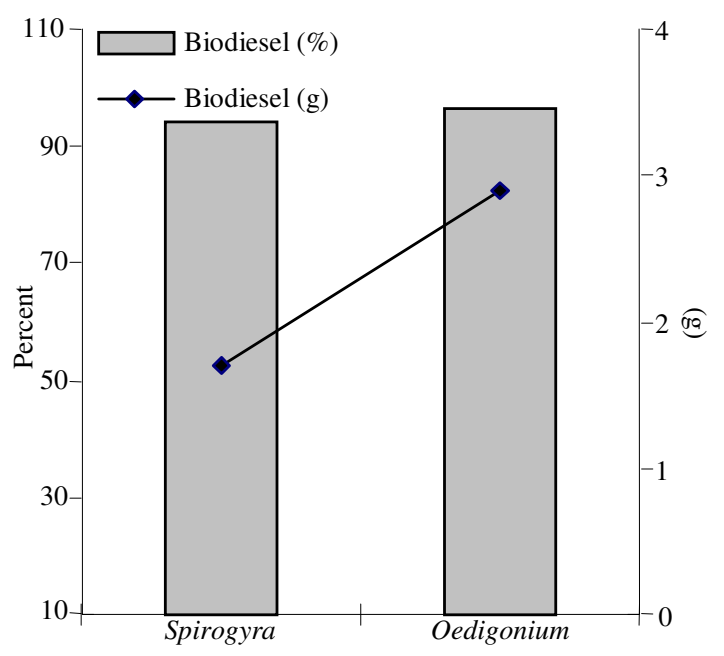

Fig. 1: Biodiesel production in Spiroyra and Oedigonium sp.

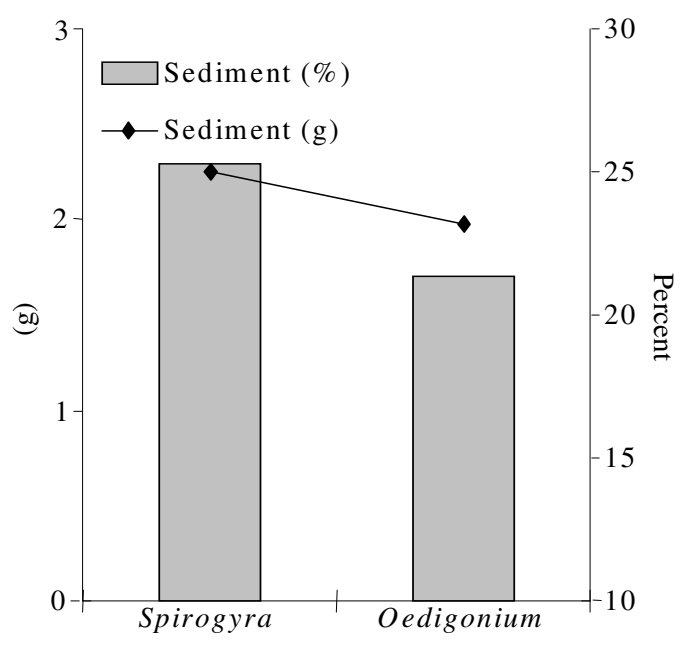

Fig. 2: Semiments (glycerine ) after algal biodiesel extraction from Spirogyra and Oedogonium sp.

Moreover, sediment (glycerine, pigments and other elements) were higher in Spirogyra than in Oedogonium sp. (Fig. 2). There was no significantly difference in $\mathrm{pH}$ between both species (Fig. 3). In Fig. 4 photo graph shows esterification (biodiesel and residues

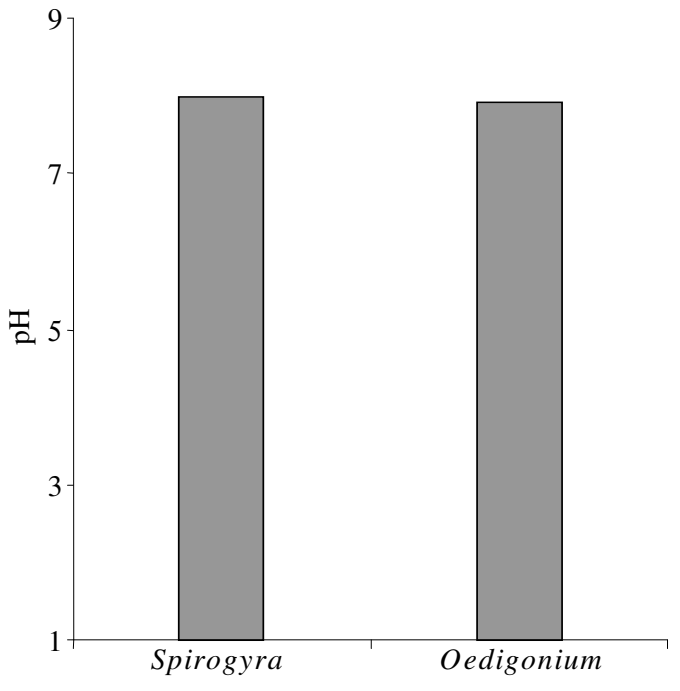

Fig. 3: Determination of $\mathrm{pH}$ from algal biodiesel

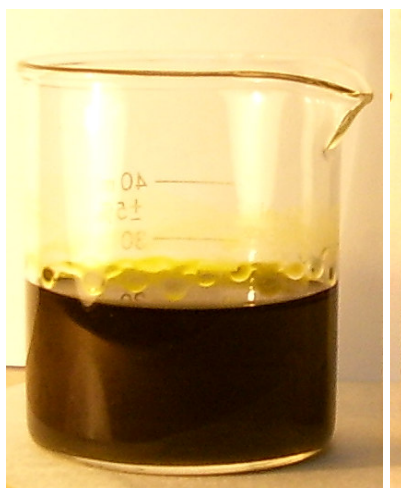

(a)

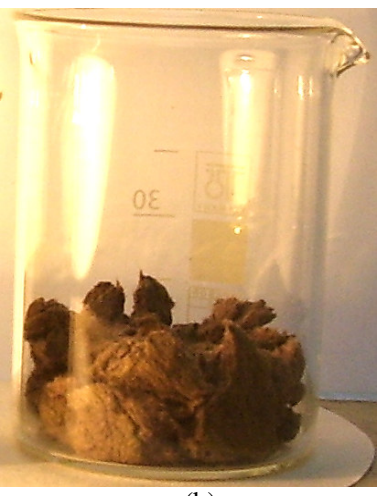

(b)

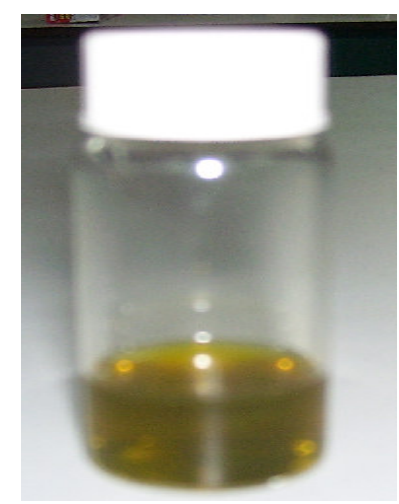

(c)

Fig. 4: Photo graphs show esterification (biodiesel and residues layer), biomass (after oil extraction) and biodiesel production with color (a): Transesterification (b): Biomass (c): Algal biodiesel 
layer), biomass and biodiesel production and color. Therefore, our results prove that biodiesel can be produced from macro algae though it contains lower lipid content than micro algae. In addition, it seems that Oedogonium sp. is higher biodiesel containing algae than spirogyra sp. Finally we strongly recommend that biodiesel can be produced from macroalge. By this way algae can be used as renewable source.

Biodiesel can be produced from macro algae because of lipid contents. Sijtsma and Swaaf ${ }^{[20]}$ stated that docosahexaenoic acid (DHA) was a polyunsaturated fatty acid composed of 22 carbon atoms and six double bonds that belonged to the socalled $\omega-3$ group. They also reported that fish oil was the major source of DHA, but alternatively it might be produced by using of microorganisms. Marine microorganisms might contain large quantities of DHA and were considered a potential source of this important fatty acid. Some of these organisms could be grown heterotrophically on organic substrates without light. It has been reported that macro algae contain lipid content of $1.3-7.8 \%(\mathrm{dw})$. In addition in heterotrophic condition lipid content can be more in algae ${ }^{[21]}$. Pohl and Zurheide $^{[22]}$ reported that lipidsof some macroalgae (seaweeds) was reported to be very high, up to $51 \%$ of total fatty acids. Vincecate ${ }^{[23]}$ suggested that seaweeds contain about $5.5 \%$ oil. Heterotrophic growth of certain marine eukaryotes, such as the microalgae, is enhanced in this medium. The samples harvested from these examples produce lipid fractions containing Omega-3 fatty acids. After extraction and esterification to form the methyl esters, gas chromatographic analyses show that the $\omega-3$ fatty acids may constitute as much as 10 to $50 \%$ of the total fatty acid fraction. They are generally contained in phospholipids, glycolipids, mono, or triglycerides and sulfolipids, or as the free acids, but are not limited to these forms ${ }^{[24]}$. Spolaore et al. ${ }^{[6]}$ evaluated that microalgae can provide several different types of renewable biofuels. Many researchers reported that biodiesel was derived from microalgal oil ${ }^{[11,12,13,17]}$.

The transesterification of used oil produced biodiesel by, using an alkaline catalyst, $\mathrm{KOH}^{[25]}$. Two types of used oils (partially hydrogenated soybean oil and margarine) were transesterified with methanol, ethanol, 1-propanol, 2-propanol, 1-butanol and 2-ethoxyethanol. Rose and Norris ${ }^{[26]}$ have compared two catalysts such as $\mathrm{KOH}$ and a combination of barium and calcium acetate for the preparation of methyl esters from waste cooking oil. Basu and Norris ${ }^{[27]}$ have developed a process to produce esters from feedstocks that have a high FFA content, diglycerides and monoglyerides, using calcium and barium acetate as a catalyst. Zhang et al. ${ }^{[28]}$ developed four different continuous process flow sheets for biodiesel production from virgin oil or waste vegetable oil using alkaline or acidic conditions. Yusuf ${ }^{[29]}$ explained about biofuel from microalgae. He mentioned that biodiesel derived from oil crops is a potential renewable and carbon neutral alternative to petroleum fuels. Microalgae appear to be the source of renewable biodiesel that is capable of meeting the global demand for transport fuels. Like plants, microalgae use sunlight to produce oils but they do so more efficiently than crop plants. Oil productivity of many microalgae greatly exceeds the oil productivity of the best producing oil crops.

\section{CONCLUSION}

Algae are an economical choice for biodiesel production, because of its availability and low cost. Our results prove that biodiesel can be produced from macroalge. In this way algae can be used as renewable energy. Many researchers reported that microalgae might better for higher biodiesl production. But research has not done yet in this regard. So our results newly highlighted by producing biodiesel from macroalgae though it contains lower lipid content. Further research should be done having macroalgae and microalgae to compare the ratio of biodiesel production, chemical analysis and statistical significance.

\section{ACKNOWLEDGMENT}

The financial support for this project from Science Fund, Mosti, Malaysia funding is gratefully acknowledged.

\section{REFERENCES}

1. Goldemberg, J., 2000. World Energy Assessment, Preface.United Nations Development Programme, new York, NY, USA.

2. Kulkarni, M.G. and A.K. Dalai, 2006. Waste cooking iol-an economical source for biodiesel: A review. Ind. Eng. Chem. Res., 45: 2901-2913.

3. Klass, L.D., 1998. Biomass for Renewable Energy, Fuels and Chemicals, Academic Press, New York, pp: 1-2.

4. Turkenburg, W.C., 2000. Renewable energy technologies. In: Goldemberg, J. (Ed). World Energy Assessment, Preface. United Nations Development Programme, New York, USA, pp: 219-272. 
5. Lang, X., A.K. Dalai, N.N. Bakhshi, M.J. Reaney and P.B. Hertz, 2002. Preparation and characterization of biodiesels from various BioOils. Bioresour. Technol., 80: 53-62.

6. Spolaore, P., C. Joannis-Cassan, E. Duran and A. Isambert, 2006. Commercial applications of microalgae. J. Biosci. Bioeng., 101: 87-96.

7. Sharif, A.B.M.H, A.B. Nasrulhaq, H.A.M., Majid, S. Chandran and R. Zuliana, 2007. Biodiesel production from waste cooking oil as environmental benefits and recycling process. A Review. Asia Biofuel Conference Book. Dec. 11-13. Singapore.

8. Hall, D.O., H.E. Mynick and R.H. Williams, 1991. Cooling the greenhouse with bioenergy. Nature, 353: 11 .

9. Macedo, I.D.C., 199. Energy from biomass and wastes. Biomass Bioenergy, 3: 77-80.

10. Shay, E.G., 1993. Diesel fuel from vegetable oils: Status and Opportunities. Biomass Bioenergy, 4: 227-242.

11. Thomas, F.R., 2006. Algae for liquid fuel production Oakhaven Permaculture center. Retrieved on 2006-12-18. Permaculture Activist, 59: $1-2$.

12. Roessler, P.G., L.M. Brown, T.G. Dunahay, D.A. Heacox, E.E. Jarvis and J.C. Schneider, 1994. Genetic-engineering approaches for enhanced production of biodiesel fuel from microalgae. ACS Symp Ser. 566: 255-270.

13. Banerjee, A., R.S. harma, Y. Chisti and U.C. Banerjee, 2002. Botryococcus braunii: A renewable source of hydrocarbons and other chemicals. Crit. Rev. Biotechnol., 22: 245-279.

14. Gavrilescu, M. and Y. Chisti, 2005. Biotechnology-a sustainable alternative for chemical industry. Biotechnol. Adv., 23: 471-99.

15. Fedorov, A.S., S. Kosourov, M.L. Ghirardi and M. Seibert, 2005. Continuous $\mathrm{H}_{2}$ photoproduction by Chlamydomonas reinhardtii using a novel twostage, sulfate-limited chemostat system. Appl. Biochem. Biotechnol., 124: 403-12.

16. Kapdan, I.K. and F. Kargi, 2006. Bio-hydrogen production from waste materials. Enzyme Microbiol. Technol., 38: 569-82.

17. Chisti, Y., 1980-1981. An unusual hydrocarbon. J. Ramsay Soc., 27-28: 24-26.
18. Sawayama, S., S. Inoue, Y. Dote and S.Y. Yokoyama, 1995. $\mathrm{CO}_{2}$ fixation and oil production through microalga. Energy Convers Manage., 36: 729-31.

19. National Biodiesel Board, 2002. USA. Available in www.biodiesel.org/ .

20. Sijtsma, L. and M.E. Swaaf, 2004. Biotechnological production and applications of the $\omega$-3-polyunsaturated fatty acid docosahexaenoic acid. Applied Microbiol. Biotechnol., 64: 146-153.

21. Renaud, S. and J. Luong-Van, 2006. Seasonal variation in the chemical composition of tropical australian marine macroalgae. J. Applied Phycol., 18: 381-387.

22. Pohl, P. and F. Zurheide, 1979. Fatty acids and lipids of marine algae and the control of their biosynthesis by environmental factors. MarineAlgae in Pharmaceutical Science, H. Hoppe et al. (Eds.), W. de Gruyter, Berlin, pp: 473-524.

23. Vincecate, G., 2006. Seaweed with more than $5.5 \%$ Oil. Sci. Biology., <http://floatingislands.com/ seaweed-oil/>.

24. Long, T.V., 1989. Microorganism prodution of Omega-3 (N-3) lipids. World International Property Organization. International Search Report. LU, USA.

25. Nye, M.J., T.W. Williamson, S. Deshpande, J.H. Schrader, W.H. Snively and T.P. Yurkewich, 1983. Conversion of used frying oil to diesel fuel by transesterification: Preliminary tests. J. Am. Oil Chem. Soc., 8: 1598-1601.

26. Rose, P. and M. Norris, 2002. Evaluate biodiesel made from waste fats and oils. Final Report, Agricultural Utilization Research Institute, Crookston, MN, USA.

27. Basu, H.N. and M.E. Norris, 1996. Process for production of esters for use as a diesel fuel substitute using a non-alkaline catalyst. US Patent No. 5, 525, 126, June 11.

28. Zhang, Y., M.A. Dube, D.D. McLean and M. Kates, 2003. Biodiesel production from waste cooking oil: 1. Process Design and Technological Assessment. Bioresour. Technol., 89: 1-16.

29. Yusuf, C., 2007. Biodiesel from microalgae. Biotechnol. Advances, 25: 294-306. 